\title{
Additive Manufacturing of PE/Fluorouracil Waffles for Implantable Drug Delivery in Bone Cancer Treatment
}

\author{
G. V. Salmoria ${ }^{1 *}$, F. E. Vieira ${ }^{2}$, G. B. Ghizoni ${ }^{3}$, I. M. Gindri ${ }^{4}$, L. A. Kanis ${ }^{5}$ \\ ${ }^{1,2,3}$ NIMMA, Department of Mechanical Engineering, Federal University of Santa Catarina, 88040-900, Florianópolis, SC, \\ Brazil \\ ${ }^{1,4}$ Biomechanics Engineering Laboratory, University Hospital (HU), Federal University of Santa Catarina, 88040-900, \\ Florianópolis, SC, Brazil \\ ${ }^{5}$ Grupo de Desenvolvimento em Tecnologia Farmacêutica, Universidade do Sul de Santa Catarina, 88504-900, Tubarão - SC \\ - Brazil
}

\begin{abstract}
In this study, implantable polyethylene/fluorouracil waffles were additively manufactured by selective laser sintering using different laser energy densities. SEM-EDS revealed a porous morphology for both PE and PE/FU waffles. High dispersion of fluorouracil particles were observed in samples prepared under different conditions. The PE/FU waffles manufactured at $5 \mathrm{~W}$ had the highest flexural modulus, probably due to better PE particle coalescence, higher sinter degree and the dispersion of FU particles in the co-continuous porous PE matrix. The PE/FU waffles showed an initial burst as well as a rapid drug released, which are desirable characteristics for cancer treatment. This profile provides a high initial concentration of the drug in the cancer cells and a subsequent controlled release sustaining levels of the chemotherapeutic agent in the region of the bone tumor.
\end{abstract}

Keywords - Polyethylene/fluorouracil, Implantable drug delivery, Cancer treatment, Selective laser sintering.

\section{INTRODUCTION}

Additive Manufacturing, also known as 3D printing, enables the fast processing of three-dimensional devices from different materials and blends. This technology is also known for overcoming geometry limitations that are characteristic of conventional manufacturing techniques and it is able to produce more complex architectures. Selective laser sintering (SLS) is a type of Additive Manufacturing that creates objects, layer by layer, through the processing of powder materials using infrared laser beams. [1-3]. The microstructures of samples prepared via SLS depend on the process parameters (laser power, scan speed and spot diameter of the laser beam, and bed temperature) and the properties of the powder. For example, the particle shape and size distribution influence the powder packing density, while the melting flow behavior and the thermal stability determine the laser power and scan speed [4-10]. In recent years, SLS has demonstrated its potential in the biomedical field, for applications in bone tissue engineering, and for manufacturing drug delivery devices (DDDs) [5-10].

Cancer is a public health concern worldwide and causes more than 600,000 deaths per year, only in the United States. The conventional approach to treat this disease includes tumor removal followed by chemotherapy or radiotherapy. However, resection surgery is not always an alternative, as observed in some cases of colon cancer metastases in which only 3.5-6.4\% of the patients are eligible for tumor removal. Furthermore, current drugs used in the systemic treatments are not specific to cancer cells and end up causing toxicity to healthy cells and tissues [11-13]. Under this scenario, intratumoral drug delivery devices have emerged as a powerful strategy for localized treatment of solid tumors, promising to substantially improve the therapeutic outcomes for several kinds of cancer. This technology allows for controlled and sustained release of the drug into the solid tumors or in the resection cavities, which results in a safer and more effective strategy [14-16].

Bone cancer usually occurs in mature/old people, except osteosarcoma, which is typically diagnosed in young people (10-20 years old) and rarely in old people [17], in the extremity of the long bones, especially in the femur [18]. There are 45 main types of primary bone tumor, the most important being osteosarcoma (35.1\% of the primary bone tumors), followed by chondrosarcoma, Ewing's sarcoma, and chondroma. By sex, males are more exposed to bone cancer ( $4 \%$ incidence in males compared to 3\% in females)[18]. The implantation of drug delivery systems at the tumor site led to a reduction in dose of the antitumor agent, and consequently the risk of systemic toxicity decreased drastically compared with conventional systemic administration. Itokazu et al developed some drug-delivery systems and proved that porosity and pore size influenced the release rate of both antitumor agents [19]. The improved contact of antitumor agents with tumoral cells is expected to reduce the recurrence and metastasis of cancer [20].

5-Fluorouracil (5-Fluoro-1H, 3H-pyrimidine-2,4-dione, 5-FU) is a traditional drug used in the treatment of many cancers. Its mechanism of action is based on the inhibition of the enzyme denominated thymidylate synthase (TS), which works in the 
synthesis of the nucleotides required for DNA and RNA replication. 5-FU is used as a systemic drug for chemotherapy as well as in the formulation of drug delivery systems where good outcomes have been observed [21-24]. On the other hand, polyethylene (PE) is a bio-inert olefin approved by FDA for use in the human body as a medical device. Drug delivery systems using PE have been proposed due to its biocompatibility and resistance to the biological environment [25, 26]. The drug can be physically mixed with this polymer and then delivered to the surrounding environment via diffusion.

In this study, polyethylene/fluorouracil (PE/FU) waffles were prepared by SLS using different laser energy densities. The morphological characteristics, mechanical properties and drug release of the waffles were evaluated and correlated with the processing conditions. The particle size and shape, along with the laser power, were used to tune the porosity of polyethylene matrix manufactured by SLS and, consequently, to control the properties for potential biomedical applications.

\section{EXPERIMENTAL}

\subsection{Materials}

The polymeric powder used in this study was commercial polyethylene (HD 7555, Ipiranga S.A.) with an average molecular weight of 140,000 to $250,000 \mathrm{~g} / \mathrm{mol}$, melting temperature (Tm) of $133{ }^{\circ} \mathrm{C}$, melt flow index of $2.65 \mathrm{~g} / 10 \mathrm{~min}$, and density of $0.89 \mathrm{~g} / \mathrm{cm}-3$ at $25{ }^{\circ} \mathrm{C}$. The particle size range used in this study was from 125 to $212 \mu \mathrm{m}$. The fluorouracil (FU) was obtained from Hubei Gedian Pharmaceutical Co with a melting temperature of $282{ }^{\circ} \mathrm{C}$. The powder blend was prepared by mechanical mixing in a Y-type rotator for 10 minutes at $30 \mathrm{rpm}$.

\subsection{Waffles Manufactured by Selective Laser Sintering}

The pure $\mathrm{PE}$ and $\mathrm{PE} / \mathrm{FU}$ waffles $(35 \times 5 \times 1.4 \mathrm{~mm})$ were sintered in a selective laser sintering system with a $9 \mathrm{~W}$ power $\mathrm{CO} 2$ laser and laser beam diameter of $250 \mu \mathrm{m}$. This study was performed in the open air and the powder bed temperature was 45 ${ }^{\circ} \mathrm{C}$. The laser scanning speed was maintained at $350 \mathrm{~mm} / \mathrm{s}$. The building layer thickness used was $250 \mu \mathrm{m}$ and the spacing between the laser scans was $125 \mu \mathrm{m}$. The laser density energies to manufacture the waffles are shown in Table 1 .

TABLE 1

PURE PE AND PE/FU WAFFLES MANUFACTURED WITH DIFFERENT LASER ENERGY.

\begin{tabular}{|c|c|c|}
\hline Waffle & Fluorouracil content $(\%)$ & Laser power $(\mathbf{W})$ \\
\hline $\mathrm{PE}$ & 0 & 3.0 \\
\hline $\mathrm{PE}$ & 0 & 5.0 \\
\hline $\mathrm{PE} / \mathrm{FU}$ & 10 & 3.0 \\
\hline $\mathrm{PE} / \mathrm{FU}$ & 10 & 5.0 \\
\hline
\end{tabular}

\subsection{Infrared and Near-Infrared Spectroscopy}

Infrared spectra of pure and processed materials were obtained using a Perkin-Elmer Frontier MIR/NIR spectrophotometer in the attenuated total reflectance (ATR) mode. For each sample 20 scans at a resolution of $4 \mathrm{~cm}^{-1}$ were obtained. Near infrared was also performed using a NIR Analyzer in the reflectance mode from 1000-2500 nm. 20 scans were obtained for each sample.

\subsection{Scanning Electron Microscopy (SEM)}

The morphology of the waffles were examined by an XL 30 Phillips scanning electron microscopy (SEM). The specimens were coated with gold in a Bal-Tec Sputter Coater SCD005.

\subsection{Differential Scanning Calorimetry (DSC)}

Differential scanning calorimetry (DSC) curves were obtained using a differential scanning calorimeter (Perkin Elmer) from 0 to $300{ }^{\circ} \mathrm{C}$ at a heating rate of $10{ }^{\circ} \mathrm{C} / \mathrm{min}$. The average sample size was $5 \mathrm{mg}$ and the nitrogen flow-rate was $25 \mathrm{~cm}^{3} / \mathrm{min}$.

\subsection{Mechanical tests}

A DMA Q800 system of TA instruments with a single cantilever clamp was used for the mechanical tests of the SLS waffles $(35 \times 5 \times 1.4 \mathrm{~mm})$. A ramp of $2 \mathrm{~N} / \mathrm{min}$ from 0 to $18 \mathrm{~N}$ was applied for the quasi-static flexural tests. The fatigue test was performed applying an oscillatory deformation. The amplitude used was $750 \mu \mathrm{m}$ in both directions, under a frequency of 1 $\mathrm{Hz}$, at $35^{\circ} \mathrm{C}$. 


\subsection{Drug release and Recovery of incorporated Fluorouracil}

The dry specimens with known drug content and thickness were immersed in a 50-mL phosphate buffer solution (PBS, $\mathrm{pH}=$ 7.4) (to maintain sink conditions), and shaken horizontally in a Dubnoff bath (Quimis S.A, Brazil) at a rate of $60 \mathrm{rev} / \mathrm{min}$ to minimize the boundary effect, and $37.0 \pm 0.5^{\circ} \mathrm{C}$. The total receptor solution volume was removed periodically and replaced with fresh solutions. After suitable dilution with the buffer solution, the total drug release was obtained using a previously prepared calibration curve (five dilutions between 0.0020 and $0.0220 \mathrm{mg} / \mathrm{mL}$ ) using a UV-Vis spectrophotometry at $\lambda_{\max }$ of $265 \mathrm{~nm}$, on a Hitachi 2010 double-beam UV-visible spectrophotometer.

For the recovery test, waffle segments obtained from three different portions of the total material produced under each condition were collected. Each piece was weighed and cut into smaller pieces to increase the surface area in contact with the solvent (10 mL of methanol; in triplicate). Samples were kept in an ultrasonic bath for $2 \mathrm{~h}$ and then analyzed by UV-vis spectrophotometry at $\lambda \max$ of $265 \mathrm{~nm}$

\section{RESULTS AND DISCUSSION}

$\mathrm{PE}$ and PE/FU waffles were prepared using additive manufacturing under two laser power conditions, $3 \mathrm{~W}$ and $5 \mathrm{~W}$. The morphological characteristics of each sample, as well as the chemical composition, were investigated using SEM-EDS. Furthermore, the crystallinity, mechanical properties and drug delivery profiles of the samples were also evaluated to understand the effect of the processing parameters on the characteristics of the materials.

The images of PE and PE/FU waffles processed under different conditions are shown in Figure 1 (A-D). The waffles showed coalescence of particles, uniform morphology, and interconnected pores distributed within the PE matrix, all of which are important characteristics in materials to be used in implantable drug delivery devices. The PE waffles produced with the lower laser energy showed a lower degree of sintering with the formation of small necks between the particles (Figure 1, A). On the other hand, the PE/FU waffles, particularly those formed at $5 \mathrm{~W}$, showed co-continuous phases and an extensive neck formation between the particles (Figure 1, D). PE/FU waffles also demonstrated greater particle coalescence probably due to the better laser absorption by the fluorouracil particles.
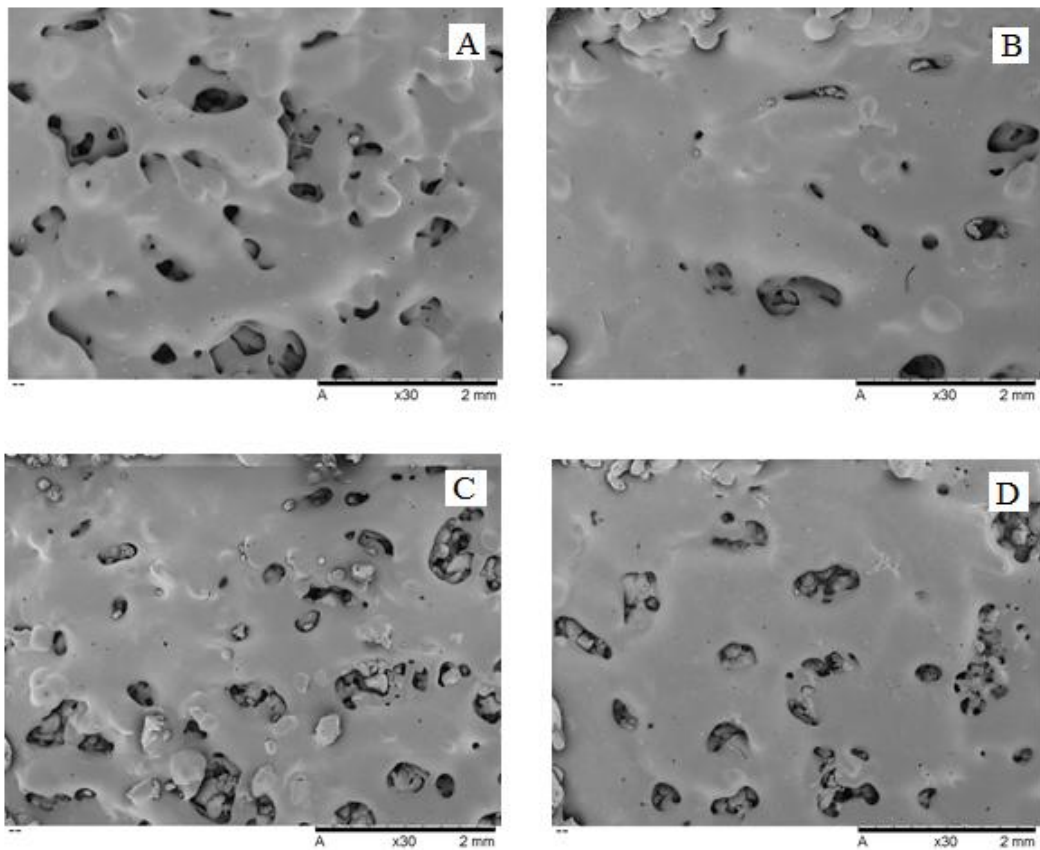

\section{FIGURE 1. SURFACE MICROGRAPHS OF PURE PE AND PE/FU WAFFLES SINTERED USING DIFFERENT POWER CONDITIONS: PE 3W (A), PE 5W (B), PE/FU 3W (C), and PE/FU 5W (D).}

The micrographs of PE/FU waffles, the EDS of nitrogen atom contrast, and nitrogen chart are shown in Figure 2. Small particles of fluorouracil were observed throughout the polyethylene matrix, demonstrating the good drug distribution for both processing conditions (Figure 2 A-D). The EDS analysis also revealed the ratio of carbon, oxygen, nitrogen and fluorine atoms present in the PE matrix as well as in the FU particles (Figure $2 \mathrm{E}$ ). 

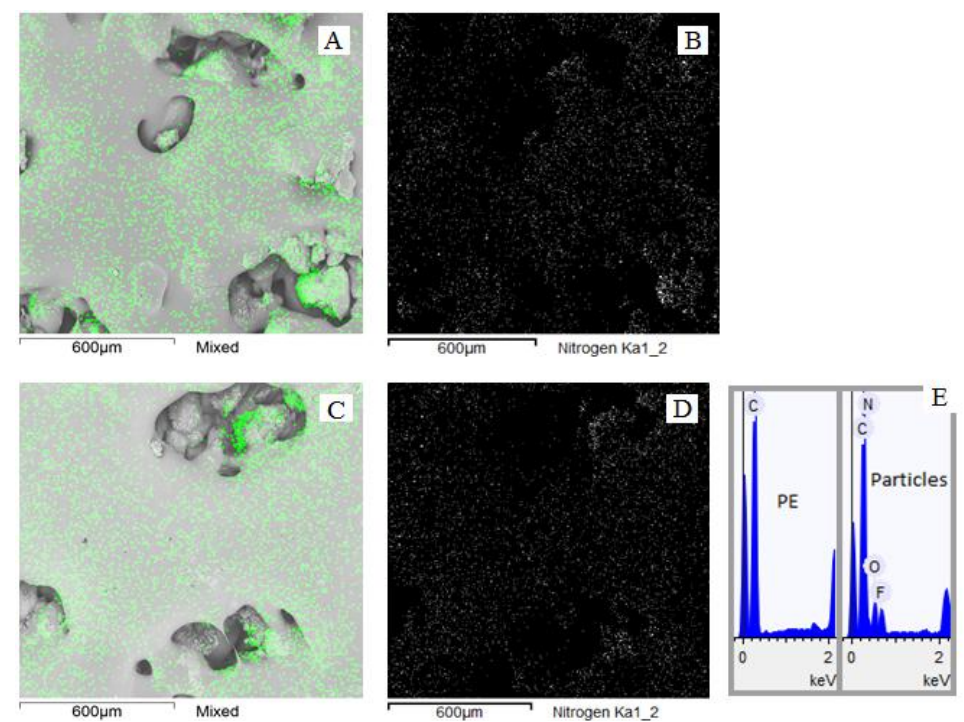

FIGURE 2. SURFACE MICROGRAPHS PRESENTING THE EDS NITROGEN CONTRAST AND CHART OF PE/FU WAFFLES SINTERED UNDER DIFFERENT POWER CONDITIONS: PE/FU 3W (A AND B), PE/FU 5W (C AND D), AND THE EDS COMPOSITION OF PE MATRIX AND FU PARTICLES IN THE WAFFLE (E).

To confirm the chemical structure and evaluate the potential intermolecular interactions between the polymer and drug, pure FU, PE waffles and PE/FU waffles were investigated using FTIR (Figure 3). The FU spectrum demonstrated absorption peaks characteristic of this compound and in agreement with the literature [25]. The $=\mathrm{C}-\mathrm{H}$ stretching of fluorouracil resulted in an absorption band in the 3100-3000 cm-1 region. The peaks at $2938 \mathrm{~cm}-1$ and $2831 \mathrm{~cm}+$ were ascribed to the $-\mathrm{CH} 2$ group. The stretching bands of $\mathrm{C}=\mathrm{N}$ and $\mathrm{C}=\mathrm{C}$ bonds in the ring were verified in the $1580-1650 \mathrm{~cm}-1$ region, while the vibration of $\mathrm{C}=\mathrm{O}$ bond correspond to the absorption peak at $1724 \mathrm{~cm}-1$ [25]. Additional bands at $1450 \mathrm{~cm}-1$ and $1350 \mathrm{~cm}-1$ are characteristic of substituted pyrimidine compounds as well as the peaks at $1180 \mathrm{~cm}-1$ and $1251 \mathrm{~cm}-1$, which were associated with $\mathrm{C}-\mathrm{O}$ and $\mathrm{C}-\mathrm{N}$ bond frequencies, respectively [25]. The fluorine bond (C-F) also resulted in absorption at $1230 \mathrm{~cm}^{-1}$ and in the 820-550 cm-1 region [20]. The spectra of the PE waffles (Figure 3, B and C) also corroborated with previous results from the literature. Symmetric and asymmetric stretching of $\mathrm{C}-\mathrm{H}$ in $\mathrm{CH} 2$ groups resulted in peaks at 2950 and $2850 \mathrm{~cm}-1$. Moreover, the peak 1350 and $1450 \mathrm{~cm}-1$ is related to the bending movement of $\mathrm{CH} 2$, whereas the rocking vibration of $\mathrm{CH} 2$ resulted in a peak at $720 \mathrm{~cm}-1[25,26]$.

The main peaks in the FTIR spectra for the PE/FU waffles (Figure 3, D and F) correspond to the PE matrix, due to the increased proportion of the polymeric material $(90 \mathrm{wt} \%)$ in comparison to the drug $(10 \mathrm{wt} \%)$. The presence of the drug is confirmed by a shoulder band in the $1580-1650 \mathrm{~cm}-1$ region and the peaks around $600 \mathrm{~cm}-1$, which were associated with $\mathrm{C}=\mathrm{C}$ and $\mathrm{C}=\mathrm{N}$ ring bonds and $\mathrm{C}-\mathrm{F}$ bond in the fluorouracil structure. The peaks ascribed to $\mathrm{PE}$ were monitored in $\mathrm{PE}$ and $\mathrm{PE} / \mathrm{FU}$ to investigate intermolecular interactions. No differences were observed in PE/FU in comparison to the PE waffles, suggesting the absence of intermolecular interactions between polymer and drug.

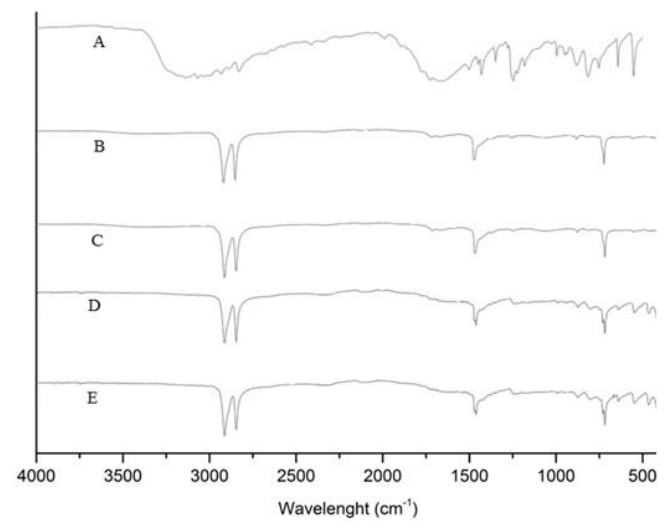

FIGURE 3. FTIR-ATR SPECTRA FOR FLUOROURACIL (A), PURE PE AND PE/FU WAFFLES SINTERED USING DIFFERENT POWER CONDITIONS: PE 3W (B), PE 5W (C), PE/FU 3W (D), AND PE/FU 5W (E). 
The full near-infrared (NIR) spectrum ranges from $700 \mathrm{~nm}$ to $2500 \mathrm{~nm}$ (14285 to $4000 \mathrm{~cm}-1)$. The results obtained for the pure FU, PE and PE/FU waffles are summarized in Figure 4 (A-E). Absorption features between 800 to $1200 \mathrm{~nm}$ correspond to combinations associated with $\mathrm{CH}, \mathrm{OH}$, and $\mathrm{NH}$ bonds and higher-order overtones. The overtone of the $\mathrm{CH}$ and $\mathrm{OH}$ groups originated information in the first overtone range (1500 to $1900 \mathrm{~nm})$. A combination of stretching and bending vibrations associated with $\mathrm{CH}, \mathrm{NH}$, and $\mathrm{OH}$ molecular groups provided information within the combination range from 2000 to 2500 $\mathrm{nm}[28,29]$. The FU spectrum revealed a broad absorption band centered at $2200 \mathrm{~nm}$, which is related to the ring structure and the urea group. This region of the NIR spectrum is dominated by second-overtone carbonyl stretching bands and N-H combination bands. This band corresponds to the combination of the symmetric and asymmetric $\mathrm{N}-\mathrm{H}$ stretching coupled with the $\mathrm{N}-\mathrm{H}$ bending vibration. Systems containing aryl rings also show absorption in the 2130- to $2160 \mathrm{~nm}$ region [27]. The first overtones of the asymmetric and symmetric $\mathrm{N}-\mathrm{H}$ stretches for fluorouracil were overlapped under the $1700 \mathrm{~nm}$ [30].

The NIR spectra of the PE waffles (Figure 4, B and C) showed a small peak at $1200 \mathrm{~nm}$ related to the second-overtone of C$\mathrm{H}$ bonds in the methylene groups, and an intense peak at 1670-1780 nm associated with the first overtone of $\mathrm{C}-\mathrm{H}$. The combination bands from the C-H bonds in the methylene groups are present from 2250 to $2300 \mathrm{~nm}$ [27]. The NIR spectra of the PE/FU waffles presented (Figure 4, D and E) the same bands as the pure PE, the major component, with an additional peak at $2330 \mathrm{~nm}$ relative to the fluorouracil presence which was $10 \%$.

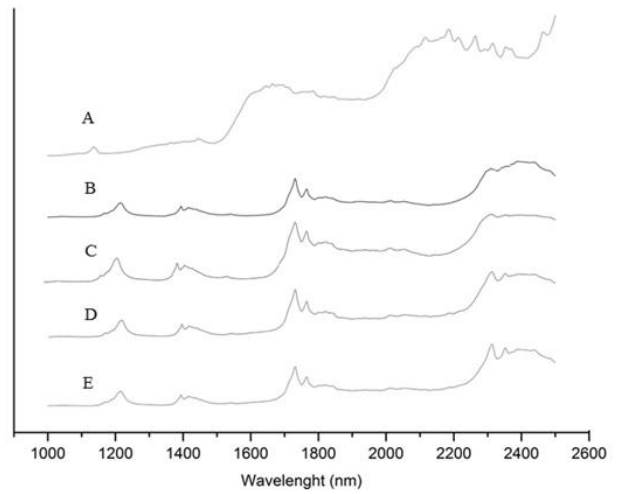

\section{FIGURE 4. NIR SPECTRA FOR FLUOROURACIL (A), PURE PE AND PE/FU WAFFLES SINTERED USING DIFFERENT POWER CONDITIONS: PE 3W (B), PE 5W (C), PE/FU 3W (D), AND PE/FU 5W (E).}

The thermal behavior of the starting materials and waffles as well as their interaction after processing was investigated using DSC. The DSC curves for the pure fluorouracil, PE and PE/FU waffles are shown in Figure 5. The FU and PE melting points were observed at $284 \mathrm{oC}$ and $134 \mathrm{oC}$, respectively. Thermal parameters obtained from the DSC curves, such as melting temperature, melting enthalpy and crystallinity are summarized in Table 2 . There was no significant variation in the melting temperature among the waffles, regardless of the processing condition. Higher laser power seems to cause an increase in the crystallinity of the PE waffles, probably due to the slower cooling rate of the waffles, but the crystallinity values for the $\mathrm{PE} / \mathrm{FU}$ waffles were the same for both temperatures. This phenomenon suggests the inexistence of a chemical interaction between fluorouracil and the PE matrix.

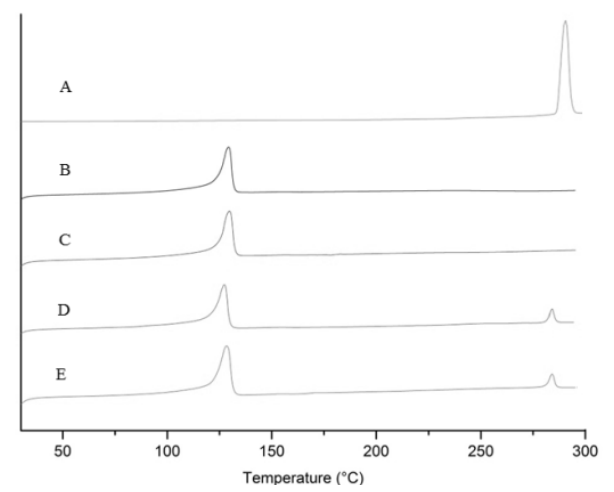

FIGURE 5. DSC THERMOGRAMS FOR PURE FLUOROURACIL (A), PE 3 W (B), PE 5 (C), PE/FU $3 W$ (D) AND PE/FU 5W (E) WAFFLES. 
TABLE 2

MELTING ENTHALPY, MELTING TEMPERATURE AND DSC CRYSTALLINITY OF THE PURE FLUOROURACIL, PE AND PE/FU WAFFLES PREPARED USING DIFFERENT LASER ENERGY.

\begin{tabular}{|c|c|c|c|c|c|c|}
\hline Specimen & $\Delta \mathbf{H}_{\mathbf{P E}}(\mathbf{J} / \mathbf{g})$ & $\mathbf{T m}\left({ }^{\mathbf{}} \mathbf{C}\right)$ & $\begin{array}{c}\mathbf{P E} \text { Crystallinity } \\
(\mathbf{\%})\end{array}$ & $\Delta \mathbf{H}_{\mathbf{F U}}(\mathbf{J} / \mathbf{g})$ & $\mathbf{T m}\left({ }^{\mathbf{0}} \mathbf{C}\right)$ & $\begin{array}{c}\text { FU content } \\
(\%)\end{array}$ \\
\hline Pure FU & - & - & - & $214 \pm 0.6$ & $285 \pm 0.3$ & 100 \\
\hline PE 3W & $158 \pm 2.2$ & $129 \pm 0.6$ & $53 \pm 2.0$ & - & - & - \\
\hline PE 5W & $135 \pm 2.4$ & $128 \pm 0.4$ & $46 \pm 3.0$ & - & - & - \\
\hline PE/FU 3W & $158 \pm 2.4$ & $129 \pm 0.4$ & $53 \pm 2.0$ & $22 \pm 0.3$ & $287 \pm 0.4$ & $10 \pm 1$ \\
\hline PE/FU 5W & $112 \pm 2.1$ & $128 \pm 0.7$ & $39 \pm 3.0$ & $24 \pm 0.3$ & $285 \pm 0.3$ & $11 \pm 1$ \\
\hline
\end{tabular}

*Crystallinity values are based on the enthalpy of melting of $100 \%$ crystalline PE, $288 \mathrm{~J} / \mathrm{g}[31]$. For the PE/FU waffles, only $90 \%$ of the weight was considered in the PE crystallinity calculus, because $10 \%$ was FU.

Besides evaluating the morphological and thermal properties of PE and PE/FU waffles, the mechanical behavior was also investigated. Flexion test curves for PE and PE/FU waffles are shown in Figure 6 and mechanical parameters are summarized in Table 3. The PE and PE/FU waffles manufactured at $3 \mathrm{~W}$ (A) showed a lower value for flexural modulus than those manufactured using a higher laser power. Moreover, the PE/FU waffles had lower flexural modulus values than the pure PE waffles processed under the same conditions. This behavior is explained based on the presence of FU particles dispersed throughout the polymeric matrix, which decreases its mechanical properties. The higher flexural modulus of the PE/FU waffles manufactured at $5 \mathrm{~W}$ (D) demonstrated that the stiffness of the PE waffles increased for samples processed with higher laser energy. This processing condition apparently yielded an increased polymer flow, greater neck formation of the particles and lower porosity.

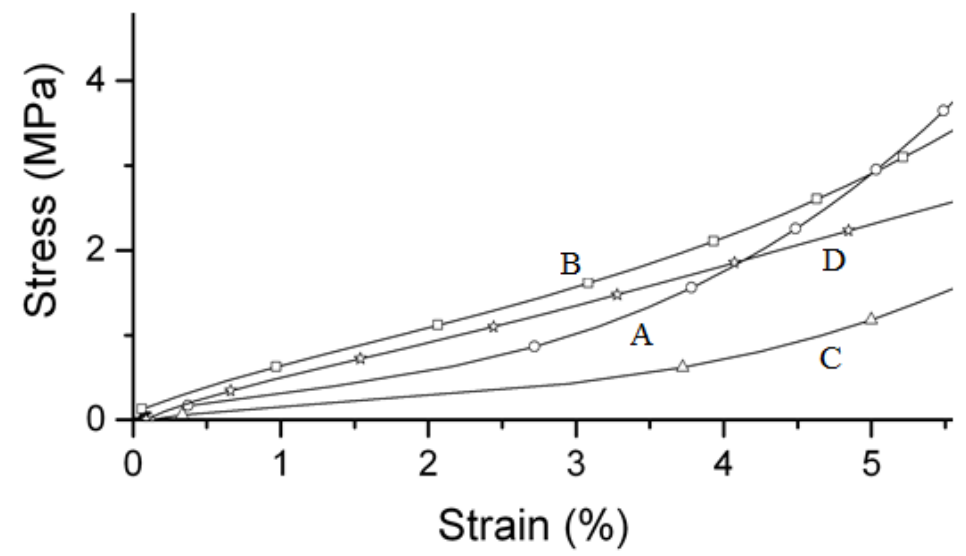

FIGURE 6. FLEXURAL TEST CURVES OF THE PURE PE AND PE/FU WAFFLES SINTERED USING DIFFERENT POWER CONDitions: PE 3W (A), PE 5W (B), PE/FU 3W (C), AND PE/FU 5W (D).

TABLE 3

FLEXURAL MODULUS AND STRENGTH OF THE PURE PE AND PE/FU WAFFLES PREPARED WITH DIFFERENT LASER SINTERING POWER.

\begin{tabular}{|c|c|c|}
\hline Specimen & Flexural Modulus (MPa) & Strength at 5\% strain (MPa) \\
\hline PE 3W & $44 \pm 3$ & $2.7 \pm 0.7$ \\
\hline PE 5W & $68 \pm 6$ & $2.8 \pm 0.8$ \\
\hline PE/FU 3W & $15 \pm 2$ & $2.1 \pm 0.6$ \\
\hline PE/FU 5W & $46 \pm 6$ & $1.3 \pm 0.6$ \\
\hline
\end{tabular}

The fatigue curves of PE and PE/FU waffles showing stress resistance as a function of the cycle number are shown in Figure 7. The laser energy was also observed to affect the fatigue resistance of the processed samples. The PE and PE/FU waffles prepared at $5 \mathrm{~W}$ (Figure A and C, respectively) showed higher fatigue strength (i.e. smaller stress variations) than the PE and $\mathrm{PE} / \mathrm{FU}$ waffles manufactured at $3 \mathrm{~W}$. The fatigue curve for PE and PE/FU waffles showed lower stress variations and higher fatigue resistance up to 1000 cycles. This increased flexibility may be associated with the lower sinter degree and stiffness of samples processed under these conditions. 


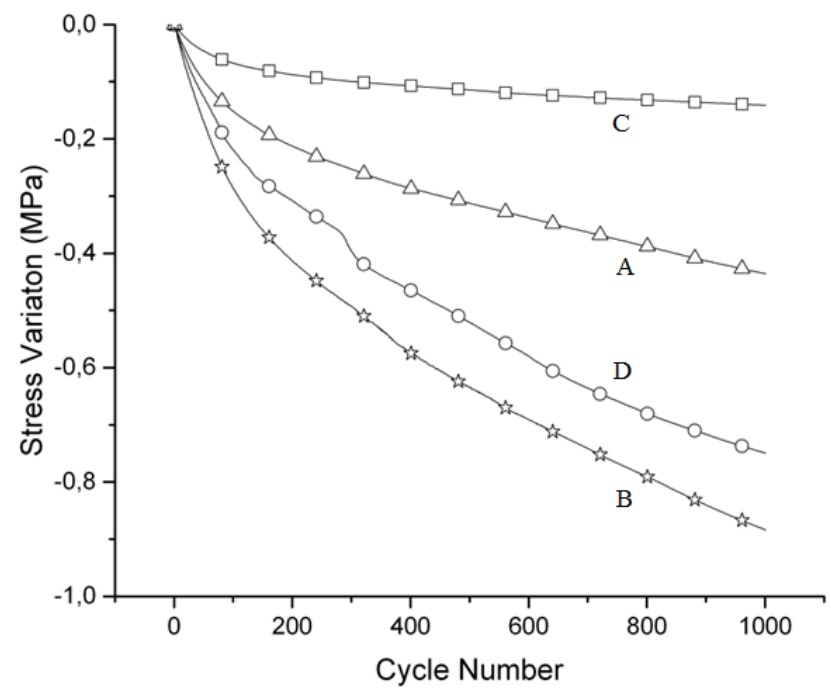

\section{FIGURE 7. FATIGUE TEST CURVES OF THE PURE PE AND PE/FU WAFFLES SINTERED USING DIFFERENT POWER CONDITIONS: PE 3W (A), PE 5W (B), PE/FU 3W (C), AND PE/FU 5W (D).}

Finally, the effect of processing conditions on the drug release profile was evaluated using UV-Vis. The drug release profiles of the PE/FU waffles are shown in Figure 8. Overall, a rapid drug release was observed for the waffles manufactured using both $3 \mathrm{~W}$ and $5 \mathrm{~W}$ and the total release was accomplished after 2 days. The initial burst, with cumulative values of around 50 $\mathrm{mg} / \mathrm{g}$ of the drug was detected in the first 4 hours. This behavior may be attributed to the hydrophilicity of FU $(12.5 \mathrm{mg} / \mathrm{ml})$ as well as the high porosity of the PE/FU waffles, which facilitates the drug dissolution in the aqueous medium. Then the release rate became slow and constant until the end of the experiment for both formulations (Figure 8A and B). The PE/FU waffles manufactured at $3 \mathrm{~W}$ presented greater drug release, which may be associated to the higher porosity of this material.

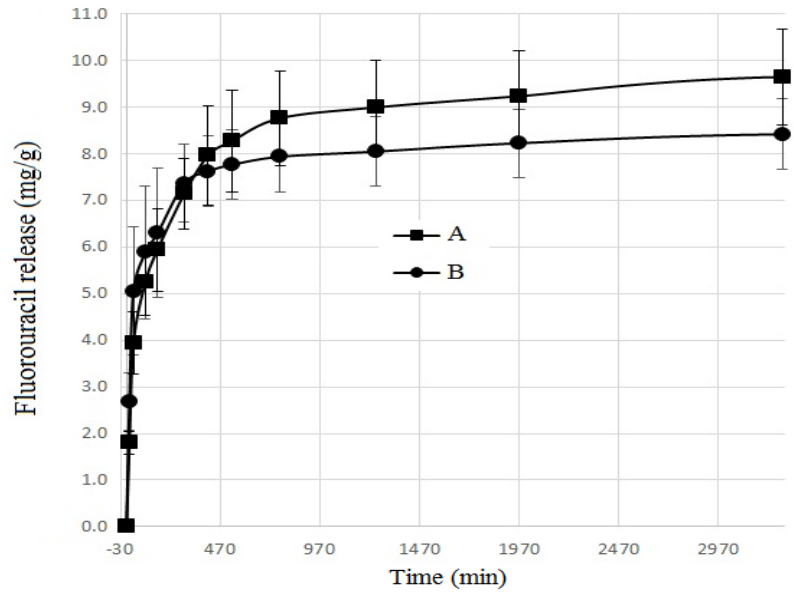

FigURE 9. FLUOROURACIL RELEASE AS A FUNCTION OF TIME FOR PE/FU WAFFLES MANUFACTURED USING 3W (A) AND 5W (B) OF LASER POWER.

The drug release pattern observed in this work is characteristic of drug delivery systems loaded with FU [32-34]. The initial concentration of FU released from the PE/FU waffles may provide a high initial concentration of the drug locally in the cancer cells following implantation. The subsequent controlled release allows for sustained levels of the chemotherapeutic agent at the cancer site $[35,36]$. These results demonstrate the potential use of PE/FU tables for treating cancer cells since FU molecules and aggregates have affinity for cancer cells and may accumulate preferentially within tumors through the delivery of the implanted waffle.

\section{CONCLUSION}

This study demonstrated additive manufacturing of PE/FU waffles through SLS with great efficiency. SEM-EDS revealed the presence of small fluorouracil particles dispersed over the surface and throughout the porous PE matrix for the PE/FU waffles processed under $3 \mathrm{~W}$ and $5 \mathrm{~W}$. The main peaks in the FTIR and NIR spectra for the PE/FU waffles were the same as those observed in the spectra for the pure PE waffles. However, the presence of the drug was confirmed by peaks at $600 \mathrm{~cm}$ - 
1 and at $2330 \mathrm{~nm}$, which were associated with C-F bond of the fluorouracil compound. The PE/FU waffles prepared using the higher laser power $(5 \mathrm{~W})$ had a higher flexural modulus, probably due to better coalescence of the PE particles, a higher sinter degree and a good dispersion of FU particles throughout the co-continuous porous PE matrix. The PE/FU waffles initially showed a rapid drug released due to the hydrophilic character of fluorouracil. This is a desirable characteristic to provide a high initial concentration of the drug locally in the cancer cells following implantation. The slow and controlled release of the drug presented subsequently by the PE/FU waffles is important to sustain appropriate levels of the chemotherapeutic agent in the region of the tumor; thus demonstrating a significant potential to improve bone cancer treatments.

\section{ACKNOWLEDGEMENTS}

The authors would like to thank PRONEX/FAPESC, CNPQ, CAPES and FINEP for their financial support.

\section{REFERENCES}

[1] Low, K.H.; Leong, K.F.; Chua, C.K.; Du, Z.H.; Cheach, C.M., (2001) Characterization of SLS parts for drug delivery devices. Rapid Prototyping Journal, Vol. 7 (5), 262-267.

[2] Leong, K.F.; Phua, K.K.S.; Chua, C.K.; Du, Z.H.; Teo, K.O.M. (2001) Fabrication of Porous Polymeric Matrix Drug Delivery Devices Using the Selective Laser Sintering Technique, Proc Instn Mech. Engrs: Part H (Journal of Engineering in Medicine), Vol $215,191-201$.

[3] Cheah, C.M., Leong, K.F., Chua, C.K., Low, K.H., Quek, H.S., (2002) Characterization of micro-features in selective laser sintered drug delivery devices. Proc. Inst. Mech. Eng. H, 216, 369-383.

[4] Yeong, W. Y.; Chua, C.K., Leong, K. F., Chandrasekaran, M., (2004) Rapid Prototyping in Tissue Engineering: Challenges and Potential. Trends in Biotechnology, Vol. 22, 643-652.

[5] Leong, K.F., Chua, C.K., Gui, W.S. and Verani W.S.G., (2006) Building Porous Biopolymeric Microstructures for Controlled Drug Delivery Devices Using Selective Laser Sintering. The International Journal of Advanced Manufacturing Technology, Vol. 31 (5), 483-489.

[6] Leong, K.F.; Wiria, F.E.; Chua, C.K.; Li, S.H., (2007) Characterization of a poly-epsiloncaprolactone polymeric drug delivery device built by selective laser sintering. Biomed. Mater. Eng., Vol. 17 (3), 147-157.

[7] Salmoria G.V., Klauss P., Zepon K., Kanis L.A., Roesler C.R.M., Vieira L.F. (2012) Development of functionally-graded reservoir of PE/PG by selective laser sintering for drug delivery devices. Virtual and Physical Prototyping, 7 (2), 107-115.

[8] Salmoria G.V., Klauss P., Zepon K.M., Kanis L.A. (2013). The effects of laser energy density and particle size in the selective laser sintering of polyethylene/progesterone specimens: morphology and drug release. International Journal of Advanced Manufacturing Technology, 66 (5), 1113-1118.doi:10.1007/s00170-012-4393-8

[9] Salmoria, G. V., Hotza, D., Klauss, P., Kanis, L. A., Roesler, C.R.M. (2014) Manufacturing of Porous Polyethylene Prepared with Different Particle Sizes and Infrared Laser Sintering Conditions: Microstructure and Mechanical Properties, Advances in Mechanical Engineering, 2014, art. no. 640496. (doi: 10.1155/2014/640496)

[10] Salmoria, G.V., Cardenuto, M.R., Roesler, C.R.M., Zepon, K.M., Kanis, L.A. (2016) PE/Ibuprofen Implants Fabricated by Selective Laser Sintering for Orbital Repair. Procedia CIRP 49, 188 - 192. https://doi.org/10.1016/j.procir.2015.11.013

[11] Alessandro Olivi · Matthew G. Ewend Tadanobu Utsuki · Betty Tyler • Abraham J. Domb Daniel J. Brat · Henry Brem (1996). Interstitial delivery of carboplatin via biodegradable Polymers is effective against experimental glioma in the rat. Cancer Chemother Pharmacol. 39, 90-96.

[12] Feng Qian, Gerald M. Saidel, Damon M. Sutton, Agata Exner, Jinming Gao (2002). Combined modeling and experimental approach for the development of dual-release polymer millirods. Journal of Controlled Release. 83, 427-435

[13] Oktay Tacara,Pornsak Sriamornsak, Crispin R. Dassa (2013). Doxorubicin: an update on anticancer molecular action, toxicity and novel drug delivery systems. Journal of Pharmacy and Pharmacology, 65, pp. 155-150.

[14] Weinberg, B. D., Ai, H., Blanco, E., Anderson, J. M. and Gao, J. (2007), Antitumor efficacy and local distribution of doxorubicin via intratumoral delivery from polymer millirods. J. Biomed. Mater. Res., 81A: 161-170. doi:10.1002/jbm.a.30914

[15] Brent D. Weinberg, Elvin Blanco, Jinming Gao (2008) Polymer Implants for Intratumoral Drug Delivery and Cancer Therapy. Journal of Pharmaceutical Sciences, Volume 97, Issue 5, Pages 1681-1702.

[16] Solorio L1, Patel RB, Wu H, Krupka T, Exner AA. (2010)Advances in image-guided intratumoral drug delivery techniques. Ther Deliv. Aug;1(2):307-22.

[17] Canadian Cancer Society. Canadian Cancer Statistics 2004. Toronto: National Cancer Institute of Canada; 2004.

[18] Bleyer A, O'Leary M, Barr R, Ries L, editors. Cancer Epidemiology in Older Adolescents and Young Adults 15 to 29 Years of Age, Including SEER Incidence and Survival: 1975-2000. Bethesda (MD): National Cancer Institute; 2006.

[19] Itokazu M, Esaki M, Yamamoto K, Tanemori T, Kasai T. (1991). Local drug delivery system using ceramics: vacuum method for impregnating a chemotherapeutic agent into a porous hydroxyapatite block. J Mater Sci-Mater M. 10(4):249-252.

[20] Itokazu M, Kumazawa S, Wada E, Wenyi Y. (1996). Sustained release of adriamycin from implanted hydroxyapatite blocks for the treatment of experimental osteogenic sarcoma in mice. Cancer Lett. 107(1):11-18. 
[21] Hiroshi Seno, Kazuki Ito, Koichi Kojima, Nobuaki Nakajima, Tsutomu Chiba (1999). Ef?cacy of an implanted drug delivery system for advanced hepatocellular carcinoma using 5-?uorouracil, epirubicin and mitomycin C. Journal of Gastroenterology and Hepatology. $14,811-816$.

[22] Shenguo Wang, Hongli Chen, Qing Cai, Jianzhong Bei (2001). Degradation and 5-Fluorouracil Release Behavior in vitro of Polyethylene/ poly(ethylene oxide)/polylactide Tri-component Copolymer. Polym. Adv. Technol. 12, 253-258.

[23] Martini LG, Collett JH, Attwood D.(2000)The release of 5-fluorouracil from microspheres of poly(epsiloncaprolactone-co-ethylene oxide). Drug Dev Ind Pharm. 26(1):7-12.

[24] Parul Singh, Gunjan Tyagi, Ranjana Mehrotra, A.K.Bakhshi (2009). Thermal stability studies of 5-?uorouracil using diffuse re?ectance infrared spectroscopy. DrugTest.Analysis 2009,1, 240-244.

[25] Gulmine J.V, Janissek P.R, Heise H.M, Akcelrud L (2002). Polyethylene characterization by FTIR. Polymer Testing, 21,5, 557-563.

[26] Paquet O., Krouit M., Bras J., Thilemans W., Belgacem M. (2010). Surface modification of cellulose by PE grafts. Acta Materialia, 58, 792-801.

[27] Edward SK, Mahpour M. The identification and origin of N-H overtone and combination bands in the near-infrared spectra of simple primary and secondary amides. Spectrochim Acta A 1973;29:1233-1246.

[28] Hazen KH, Arnold MA, Small GW. Measurement of glucose in water with first-overtone near-infrared spectra. Appl Spectrosc 1998;52:1597-1605.CrossRef

[29] Christopher V. Eddy, Mark A. Arnold (2001). Near-Infrared Spectroscopy for Measuring Urea in Hemodialysis Fluids. Clinical Chemistry, Vol. 47, Issue 7, pp 1279-1286.

[30] Crandall, E. W. and Jagtap, A. N. (1977), The near-infrared spectra of polymers. J. Appl. Polym. Sci., 21: 449-454. doi:10.1002/app.1977.070210211

[31] Mirabella, F. M. and Bafna, A. (2002), Determination of the crystallinity of polyethylene/?-olefin copolymers by thermal analysis: Relationship of the heat of fusion of 100\% polyethylene crystal and the density. J. Polym. Sci. B Polym. Phys., 40: 1637-1643.

[32] Yassin A. E.B., , Anwer M K., Mowafy H. A., El-Bagory I. M., Bayomi M. A., Alsarra I. A., (2010). Optimization of 5-fluorouracil solid-lipid nanoparticles: a preliminary study to treat colon cancer. Int. J. Med. Sci. 5 (6), 398-408. doi:10.7150/ijms.7.398.

[33] Lee, J.S., Chae, G.S., An, T.K., Khang G., Cho S.H., Lee H.B. (2003). Preparation of 5-fluorouracil-loaded poly(L-lactide-coglycolide) wafer and evaluation of in vitro release behavior. Macromolecular Research. 11, 3,183-188.

[34] Hanafy, A. F.A. H., El-Egaky A. M., Mortada S. A. M., Molokhia A. M. (2009). Development of implants for sustained release of 5 fluorouracil using low molecular weight biodegradable polymers. Drug Discoveries \& Therapeutics. 3, 6, 287-295.

[35] Sairam M. Babu V.R, Naidu B.V.K., Aminabhavi T. M. (2006). Encapsulation efficiency and controlled release characteristis of crosslinked polyacrylamide particles. Int. J. of Pharmaceutics, 320, 131-136.

[36] Gao H., Gu Y., Ping Q., (2005). The implantable 5-fluorouracil-loaded poly(l-latic acid) fibers prepared by wet-spinning from suspension. Journal of Controlled Release. 3, 23, 325-332. 